\title{
Nurses' knowledge of contents of diabetes patient education in Ondo - state, Nigeria
}

\author{
Modupe O. Oyetunde ${ }^{1}$, T T Famakinwa ${ }^{2}$ \\ 1. Department of Nursing, University of I badan, Nigeria. 2. Department of Nursing Science, Obafemi Awolowo University, \\ Ile-Ife, Nigeria.
}

Correspondence: Modupe O. Oyetunde. Address: Department of Nursing, University of Ibadan, Nigeria. Email: modupeoyetunde@gmail.com

Received: May 7, 2013

Accepted: July 29, 2013

Online Published: J anuary 23, 2014

DOI : 10.5430/jnep.v4n4p91

URL: http://dx.doi.org/10.5430/jnep.v4n4p91

\begin{abstract}
Background: Diabetes patient education is central to achieving active participation in management of diabetes. This participation is critical to quality and quantity of life among diabetic patients. However, observations show uncontrolled and complicated diabetes; noncompliance with the treatment regimen traceable to poor transfer of knowledge. The study was designed to assess nurses' knowledge of diabetes patient education in government hospitals in Ondo State.

Method: The survey consisted of Four hundred and one registered randomly selected nurses working in various units of the selected hospitals. The instrument was a validated, self administered 44 - item questionnaire developed by the researchers using the professional prompter worksheet for diabetes education and content areas of diabetes education. The questionnaire focused on four content areas of diabetes education- nutrition, exercise and activity, glucose monitoring, and foot and skin care.

Result: The result showed that the respondents were majorly females (82.3\%). Seventy two percent of the respondents had between 1year and 5years of work experience. Only $8.2 \%$ had $1^{\text {st }}$ degree. Respondents demonstrated poor knowledge in the specified content areas of diabetes patients' education. Good knowledge of nutrition was only $29.2 \%$ while that of exercise/activity was $24.9 \%$ of respondents. For glucose monitoring, only $24.9 \%$ had good knowledge while that of hygiene/foot care was $34.4 \%$ of the respondents. The mean scores for the content areas were nutrition: $51 \pm 15$; exercise/activity: 50 \pm 14 ; glucose monitoring: $50 \pm 14$ and foot and skin care: $53 \pm 16$ respectively. Respondents with one to five years work experience performed better than those with longer years of experience in the selected content areas.

Conclusion: In view of this result, it is recommended that definitive modules for educating diabetes patient be developed for each health institution and more emphasis placed on continuing education of nurses to update their knowledge about current Diabetes management.
\end{abstract}

\section{Key words}

Nurses' knowledge, Diabetes, Patient education, Nigeria

\section{I ntroduction}

Diabetes Mellitus is a worldwide problem. In Nigeria, the national prevalence of people living with diabetes is estimated at $4.7 \%$ while the average in Africa is $3.8 \%{ }^{[1,2]}$. In recent times, the rate of deaths arising from diabetes in developing 
countries is becoming worrisome, and a threat to the health care sector. The growth in diabetes prevalence and incidence accelerated in the early 1990's and this acceleration remains unabated ${ }^{[3]}$. This may not be unrelated to the changing life-styles of Nigerians ${ }^{[4,5]}$.

It is a common knowledge that the principal aim of management of diabetes is to establish and maintain metabolic control in order that treatment may save life, alleviate symptoms and prevent long - term complications ${ }^{[6]}$. As documented in Brunner and Suddarth ${ }^{[7]}$, there are five components of management for diabetes, these components are: nutrition management, exercise, monitoring, pharmacological therapy and education.

Diabetes management involves constant assessment and modification of the treatment plan by health professionals as well as daily adjustments in therapy by patient ${ }^{[8]}$. Although the health care team directs the treatment, it is the patient who is faced with the daily charge of managing the intricacies of complex therapeutic regimen ${ }^{[9]}$. For this reason, the patient and family education is an essential component of diabetes treatment ${ }^{[10,11]}$. Self-management skills are probably the major determinants of how well the health problem is controlled, and the quality of life maintained. This is particularly true for persons with diabetes. Research evidence shows that patient education has a positive effect on patient outcomes ${ }^{[12,13]}$. Ulrich et al. ${ }^{[14]}$ surmised that the contents of diabetes patient education are Meal, Move, Medication, Meter and More. These authors portend that this teaching can be done at the bedside ${ }^{[14]}$. Many reasons were attributed to poor/non performance of patient teaching, and these are majorly from systemic and personal shortfalls ${ }^{[15]}$. The American Diabetes Association suggests that diabetes education take place in three stages and is continuous ${ }^{[16,17]}$ : survival/initial stage, in-depth stage and continuous stage.

Nurses have a great deal of responsibility in providing essential information to the diabetic to enable the patient live a quality life ${ }^{[17,18]}$. The nurse, therefore, must possess the expected knowledge to enable the achievement of this goal. A well structured diabetic patient education has been identified as a potent means of helping diabetic patient achieve quality life devoid of complications ${ }^{[19]}$. Scholars ${ }^{[20-22]}$ have identified that content and context of diabetes patient education have been a major problem confronting nurses. However, it was reported in some studies ${ }^{[17,20-22]}$ that nurses demonstrated poor knowledge of diabetes.

Patient education improves life style modification and self management skills that are needed by people living with Diabetes ${ }^{[14]}$. A major responsibility of the professional nurse is helping patients gain self management skills for any chronic health problem through teaching and the counseling ${ }^{[20]}$. The increasing incidence of diabetes complications among people living with diabetes in Nigeria does not suggest a successful accomplishment of this task; hence the need to conduct this study.

\section{Aims and objectives}

The aim of the study was to assess nurses' knowledge of contents of diabetes patients' education.

The specific objectives were:

1) To determine whether or not nurses have adequate knowledge about nutrition and exercise/activity in the management of diabetes mellitus.

2) To assess whether or not nurses have adequate knowledge about glucose monitoring, foot and skin care in the management of diabetes mellitus.

\section{Method}

The study was a descriptive survey with a cross-sectional design. The study was conducted in six government hospitals in Ondo State. The participating hospitals were randomly selected out of the fifteen government hospitals in the three senatorial districts in Ondo State. 
There were five hundred and eighty nurses in the six participating hospitals at the time of data collection. Seventy five percent $(75 \%)$ of this population were randomly selected for the study because it was adjudged adequate to elicit information that the total population could have given.

Inclusion criteria were being a nurse employed to work in the hospital and willingness to give consent to participate.

\subsection{I nstrument}

The instrument was a self-developed questionnaire adapted from professional prompter worksheet for diabetes education and content areas of diabetes education. The questionnaire has two major parts, the demographic information of the respondents and the second part consisted of 40 questions on the diabetes education content areas.

Each question in section B was assigned 1mark. A good knowledge of each content area was a score of $70 \%$ and above ( $\geq$ $70 \%$ ) of the content while poor knowledge was a score of less than $70 \%$. This was because previous studies indicated that a $70 \%$ pass mark was satisfactory. The instrument was subjected to both face and content validity after which it was pre tested among twenty (25) Nurses in one of the non-participating hospitals in Ondo State and a Cronsbach's alpha coefficient score of $r=0.8$.was obtained. The nurses working in the hospital where the pre- test took place share the same characteristics with the respondents. The pre test allows researchers to reframe some ambiguous words and also to determine the length of time to complete the questionnaire.

\subsection{Procedure for data collection}

The selected hospitals were visited and the key officers were informed about the study. Permission was further obtained in addition to that of the State Hospital Management board. This provided access to the nurses in the hospitals. The rosters were studied to know the nursing work force and the pattern for each day. The roster constituted the sample frame from which $75 \%$ was selected. Researchers obtained individual consent and distributed questionnaire to every three out of four nurses in each ward and where any eligible participant declined, researchers moved on. Filled question-naire was collected before moving to the next ward this accounted for high retrieval rate. Data collection lasted six weeks.

\subsection{Ethical issues}

The permission to conduct the study was obtained from the Ondo-State Hospital Management Board, the organ that oversees the administration of the hospitals. The nurses in each setting were informed about the purpose and objectives of the study. Issues of confidentiality of person and information; voluntariness in participation; withdrawal from the study at any point if they wish were stressed. After ascertaining that participants had clear understanding of the study, consent was obtained.

\subsection{Method of data analysis}

Data analysis was done using a descriptive statistics of the statistical package for social sciences version 16 . The completed questionnaire items were checked, coded and analyzed using frequency counts and percentages.

\section{Results}

Four hundred and one (97.80\%) of the 410 questionnaire copies administered were properly filled and considered fit for analysis.

Table 1 shows the demographic distribution of respondents. Over $80 \%$ were females, and this is a reflection of preponderance of women in nursing. About $63 \%$ had dual qualification, i.e. they were registered nurses and midwives. In Nigeria, promotion and employment policy for nurses favour dual qualifications. Those working in medical wards were about $36 \%$, and about $73 \%$ had between one year and five years of work experience. This is a reflection of the structure of Nurses in 
Ondo State and most States in Nigeria. This also may not be unrelated to long unemployment period, brain drain and retirement of experienced nurses from the State just like any other State in Nigeria is experiencing. This has resulted in aggressive recruitment of nurses in the last few years.

Table 1. Respondents' Socio -Demographic Characteristics

\begin{tabular}{|c|c|c|}
\hline Variables & $\mathbf{N}$ & $\%$ \\
\hline \multicolumn{3}{|l|}{ SEX } \\
\hline Male & 71 & 17.7 \\
\hline Female & 330 & 82.3 \\
\hline Total & 401 & 100.0 \\
\hline \multicolumn{3}{|c|}{ Educational / Professional qualification background } \\
\hline Registered Nurse (RN) only & 99 & 24.7 \\
\hline Registered Midwife (RM) only & 18 & 4.5 \\
\hline Registered Nurse / Midwife (RN, RM) & 251 & 62.6 \\
\hline RN, RM, / RN, B.Sc. & 33 & 8.2 \\
\hline Total & 401 & 100.0 \\
\hline \multicolumn{3}{|l|}{ Years of Experience } \\
\hline $1-5$ years & 291 & 72.6 \\
\hline $6-10$ years & 69 & 17.2 \\
\hline Above 10 years & 41 & 10.2 \\
\hline Total & 401 & 100 \\
\hline \multicolumn{3}{|l|}{ Work units/wards } \\
\hline Medical Wards & 144 & 35.9 \\
\hline Surgical Wards & 92 & 22.9 \\
\hline Out Patient Clinics & 44 & 11 \\
\hline Accident and Emergency & 27 & 6.7 \\
\hline Operating Theatre & 36 & 9 \\
\hline Intensive Care Unit & 6 & 1.5 \\
\hline Other Units & 52 & 13 \\
\hline Total & 401 & 100 \\
\hline
\end{tabular}

Table 2 shows that about $29.2 \%$ and $24.9 \%$ of respondents had good knowledge of nutrition and exercise/ activity in diabetes patient education.

Table 2. Respondents' knowledge of Nutrition and Activity in the Management of Diabetes Mellitus

\begin{tabular}{|c|c|c|c|c|c|c|}
\hline \multirow{3}{*}{$\begin{array}{l}\text { Content areas of diabetes } \\
\text { patient education }\end{array}$} & \multicolumn{4}{|c|}{ Knowledge level } & \multirow{2}{*}{\multicolumn{2}{|c|}{ Total }} \\
\hline & \multicolumn{2}{|l|}{ Good } & \multicolumn{2}{|l|}{ Poor } & & \\
\hline & $\mathrm{N}$ & $\%$ & $\mathrm{~N}$ & $\%$ & $\mathrm{~N}$ & $\%$ \\
\hline Nutrition & 117 & $(29.2)$ & 284 & $(79.8)$ & 401 & 100 \\
\hline Exercise / Activity & 100 & $(24.9)$ & 301 & $(75.1)$ & 401 & 100 \\
\hline
\end{tabular}

Table 3 shows respondents knowledge of glucose monitoring and foot care. Respondent demonstrated poor knowledge of both content areas.

Table 3. Respondents' Knowledge of Glucose Monitoring and Foot/ Skin Care

\begin{tabular}{|c|c|c|c|c|c|c|}
\hline \multirow{3}{*}{$\begin{array}{l}\text { Content areas of diabetes } \\
\text { patient education }\end{array}$} & \multicolumn{4}{|c|}{ Knowledge level } & \multirow{2}{*}{\multicolumn{2}{|c|}{ Total }} \\
\hline & \multicolumn{2}{|c|}{ Good } & \multicolumn{2}{|l|}{ Poor } & & \\
\hline & $\mathrm{N}$ & $\%$ & $\mathrm{~N}$ & $\%$ & $\mathrm{~N}$ & $\%$ \\
\hline Glucose monitoring & 100 & $(24.9)$ & 301 & $(75.1)$ & 401 & 100 \\
\hline Hygiene / Foot Care & 138 & $(34.4)$ & 263 & $(65.6)$ & 401 & 100 \\
\hline
\end{tabular}




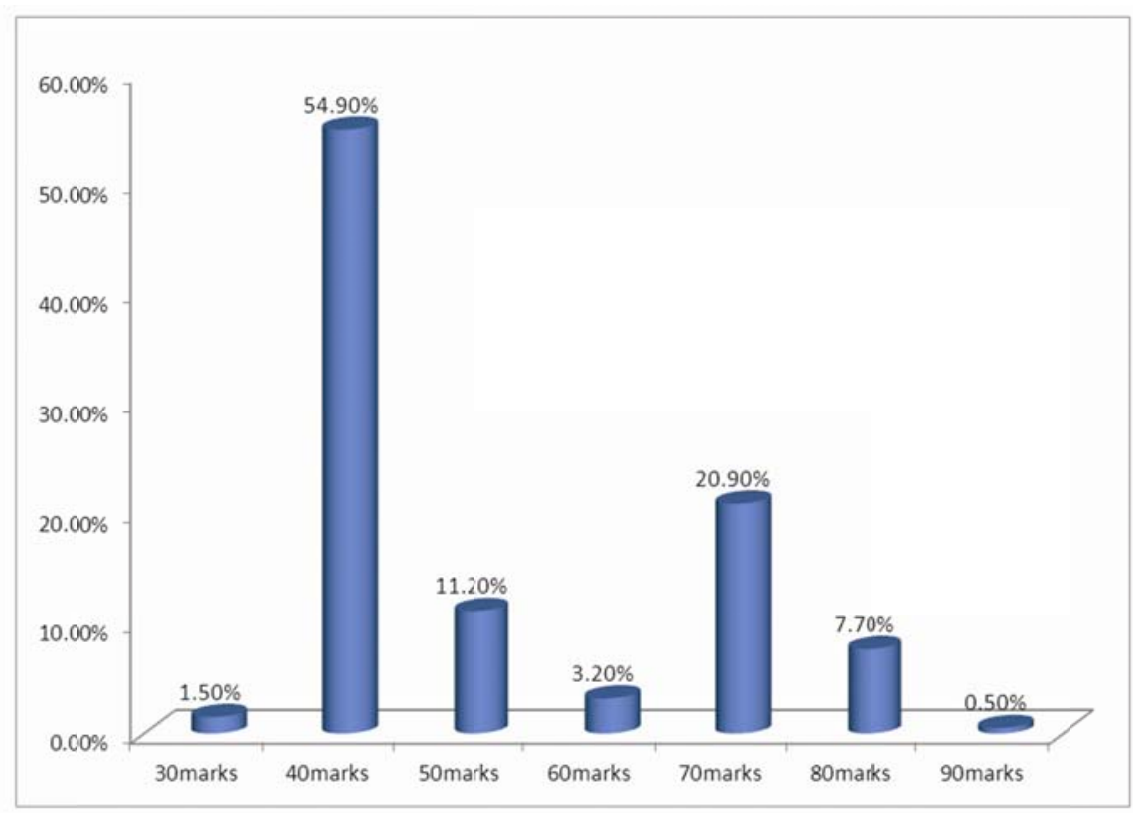

Figure 1. Nurses' knowledge of nutrition content of Diabetes patient education

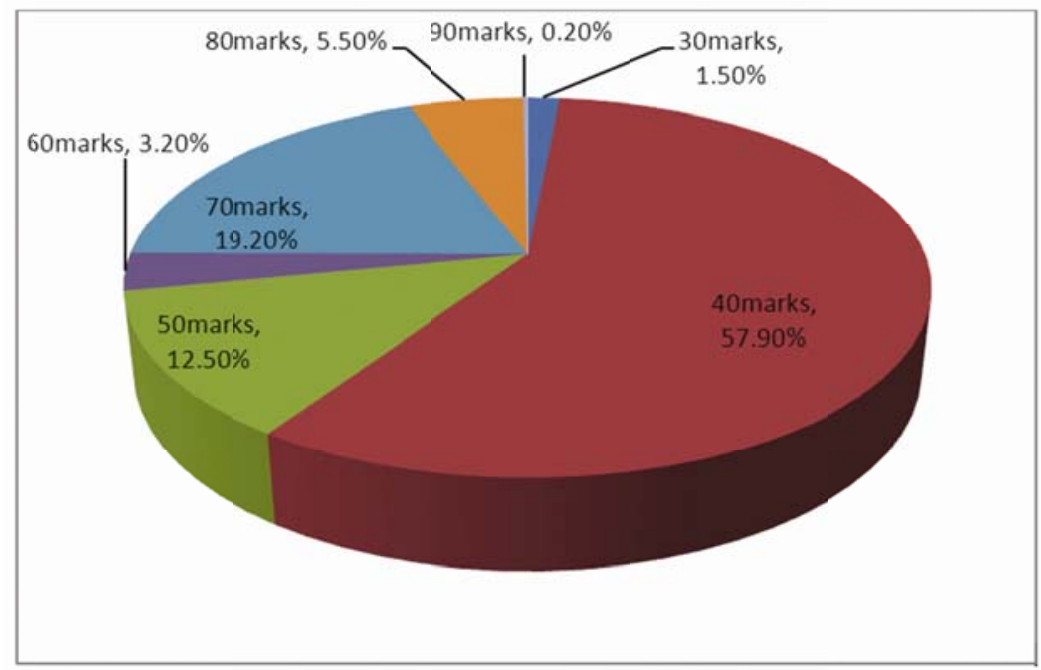

Figure 2. Nurses' knowledge of Exercise/Activity content of Diabetes patient education

Table 4 presents the respondents' knowledge of content of Diabetes patient education by their years of experience.

Table 4. Respondents' Knowledge of contents of Diabetes patient education by Years of work Experience

\begin{tabular}{|c|c|c|c|c|c|c|c|c|c|c|c|c|c|c|c|c|c|}
\hline \multirow{2}{*}{ Variable } & \multirow{3}{*}{$\begin{array}{l}\text { Level of } \\
\text { knowledge }\end{array}$} & \multicolumn{4}{|c|}{ Nutrition } & \multicolumn{4}{|c|}{ Exercise/activity } & \multicolumn{4}{|c|}{ Glucose monitoring } & \multicolumn{4}{|c|}{ Skin and foot care } \\
\hline & & \multicolumn{2}{|c|}{ Good } & \multicolumn{2}{|c|}{ Poor } & \multicolumn{2}{|c|}{ Good } & \multicolumn{2}{|c|}{ Poor } & \multicolumn{2}{|c|}{ Good } & \multicolumn{2}{|c|}{ Poor } & \multicolumn{2}{|c|}{ Good } & \multicolumn{2}{|l|}{ Poor } \\
\hline $\begin{array}{l}\text { Years of } \\
\text { experience }\end{array}$ & & $\mathbf{N}$ & $\%$ & $\mathbf{N}$ & $\%$ & $\mathbf{N}$ & $\%$ & $\mathbf{N}$ & $\%$ & $\mathbf{N}$ & $\%$ & $\mathbf{N}$ & $\%$ & $\mathbf{N}$ & $\%$ & $\mathbf{N}$ & $\%$ \\
\hline $1-5$ & & 100 & 24.9 & 191 & 47.6 & 68 & 17.0 & 223 & 55.6 & 85 & 21.2 & 206 & 51.4 & 99 & 24.7 & 192 & 47.9 \\
\hline $6-10$ & & 7 & 1.7 & 62 & 15.5 & 20 & 5.0 & 49 & 12.2 & 10 & 2.5 & 59 & 14.7 & 29 & 7.2 & 40 & 10.0 \\
\hline$>10$ & & 10 & 2.5 & 31 & 7.7 & 12 & 3.0 & 29 & 7.2 & 5 & 1.2 & 36 & 9.0 & 10 & 2.5 & 31 & 7.7 \\
\hline Total & & 117 & 29.2 & 284 & 70.8 & 100 & 25.0 & 301 & 75.0 & 100 & 24.9 & 301 & 75.1 & 138 & 34.4 & 263 & 65.6 \\
\hline
\end{tabular}


Table 5 shows that respondents' knowledge of contents of Diabetes patient education was very poor even within group.

Table 5. Respondents' knowledge of contents of Diabetes patient education within group performance

\begin{tabular}{|c|c|c|c|c|c|c|c|c|c|c|c|c|}
\hline \multirow{3}{*}{$\begin{array}{l}\text { Variable } \\
\text { Level of knowledge of } \\
\text { Contents: }\end{array}$} & \multicolumn{2}{|c|}{$\begin{array}{l}1-5 \quad \text { Year } \\
(\mathrm{N}=\end{array}$} & \multicolumn{2}{|c|}{ experience } & \multicolumn{2}{|c|}{$\begin{array}{l}\text { 6-10 Year } \\
(\mathrm{N}=69)\end{array}$} & \multicolumn{2}{|c|}{ f experience } & \multicolumn{2}{|c|}{$\begin{array}{l}>10 \quad \text { Year } \\
(N=41)\end{array}$} & of & experience \\
\hline & \multicolumn{2}{|c|}{ Good } & \multicolumn{2}{|c|}{ Poor } & \multicolumn{2}{|c|}{ Good } & \multicolumn{2}{|c|}{ Poor } & \multicolumn{2}{|c|}{ Good } & \multicolumn{2}{|c|}{ Poor } \\
\hline & $\mathbf{N}$ & $\%$ & $\mathbf{N}$ & $\%$ & $\mathbf{N}$ & $\%$ & $\mathbf{N}$ & $\%$ & $\mathbf{N}$ & $\%$ & $\mathbf{N}$ & $\%$ \\
\hline Nutrition & 100 & 34.4 & 191 & 65.6 & 7 & 10.1 & 62 & 89.9 & 10 & 24.4 & 31 & 75.6 \\
\hline Exercise/activity & 68 & 23.4 & 223 & 76.6 & 20 & 29.0 & 49 & 71.0 & 12 & 29.3 & 29 & 70.7 \\
\hline Glucose monitoring & 85 & 29.2 & 206 & 70.8 & 10 & 14.5 & 59 & 85.5 & 5 & 12.2 & 36 & 87.8 \\
\hline Skin/ foot care & 99 & 34.0 & 192 & 66.0 & 29 & 42.0 & 40 & 58.0 & 10 & 24.4 & 31 & 75.6 \\
\hline
\end{tabular}

\section{Discussion}

As earlier stated, Diabetes patient education is an important key to achieving self management skills that are much needed for glycaemic control. Patients are assisted to accept and integrate the diabetes management tasks successfully into their lifestyle in order to achieve and maintain a balanced lifestyle and optimum diabetic control. Patient teaching is a recognized independent function of the nurse. The roles of nurses in the management of diabetes include teaching of patients in acute, elderly and extended care facilities. The study was designed to achieve the following objectives:

1) To determine whether or not nurses have adequate knowledge of nutrition and exercise/activity in the management of diabetes mellitus.

2) To assess whether or not nurses have adequate knowledge of glucose monitoring, foot and skin care in the management of diabetes mellitus.

Results show that the respondents demonstrated poor knowledge in the chosen contents areas of diabetes patient education. About $29.2 \%$ of the respondents demonstrated good knowledge of nutrition while $24.9 \%$ had good knowledge of exercise/ activity on glucose control. This result is similar to previous studies that nurses had poor knowledge of diabetes ${ }^{[17]}$ contents. These two contents areas require special emphasis in diabetes management in Nigeria being a poor resource setting. The staple food is mostly carbohydrates and exercise appears to be cheap and common practice except among few. Physical exercise has a tremendous effect on Diabetes Mellitus ${ }^{[25]}$. Studies have shown that diabetic patients adhere most poorly to exercise regimens ${ }^{[14]}$ probably because they think they have enough in a setting like Nigeria. Since the nurses demonstrated poor knowledge of these content areas how can they effectively educate patients on the need to prevent complications of poor glycaemic control? This poor knowledge has translated into practice thus confirming the observations of the researchers.

The result was poor for glucose monitoring and skin/foot care. This finding portends a negative impact on patients' adherence to glucose control. Many patients do not adjust positively to lifestyle changes for a variety of reasons and the only check would have been glucose monitoring. Nurses' knowledge deficit may interfere with the success of such interventions that would necessitate frequent adjustments. Foot care is another regimen Diabetic patients adhere to most poorly. The study by Kim and $\mathrm{Oh}^{[13]}$ showed no significant adherence to foot care even after nurses educational intervention. The reason for this may be related to nurse's poor knowledge in skin and foot care and consequently inadequate patient education.

The Previous and present studies indicated that nurses knowledge of Diabetes was poor. This may be a deficiency in the nursing curricular or the emphasis on this chronic but not communicable disease. One would have expected a very good performance since majority were relatively new from school. The more experienced nurses should also have acquired knowledge in the course of their work. This result calls for an urgent intervention especially in a country where the prevalence of Diabetes is on the increase. Nurses contribute significantly to patient experience and to positive patient 
outcome hence the need for them to be knowledgeable about health promotion, health maintenance of diseases, especially the chronic diseases that require life style modifications.

\section{Conclusion and recommendations}

Nurses in this study demonstrated inadequate knowledge of diabetes patient education and same may be true of other nurses in Nigeria. No standardized professional prompter worksheet for diabetes education was found in all the health institutions used for the study. This allows variations in the content and volume of information given to patients. The patients are subjected to the individual nurse level of knowledge about diabetes patient education and a focus on areas that interest him/ her. Consequently patients are not educationally empowered to handle self care practices.

It is recommended that definitive modules for educating diabetic patients be developed for each health institution and more emphasis placed on continued education of nurses to update their knowledge about current diabetes management.

\section{References}

[1] Diabetes Atlas 4th Edition, International Diabetes Federation, 2009

[2] International Diabetes Federation (IDF) Diabetes Atlas (Internet). the 5th edition. www.diabetesatlas.org 2011

[3] Isaac Akogu. The Prevalence of Diabetes mellitus in Nigeria updates and challenges, 2010.

[4] Akogu, Isaac. The Problem of Diabetes in Nigeria. 1 Oct. 2009 EzineArticles.com. 5 Jan. 2013. Available from: http://ezinearticles.com/? The-Problem-of-Diabetes-in-Nigeria\&id=3020464.

[5] Nyenwe EA, Odia O.J, Ihekwaba A.E. Oule A and Babatunde S. Type 2 diabetes in adult Nigerians; a study of its prevalence and risk factors in Port Harcourt, Nigeria. Diabetes Research Clinical practice. 2003; 62(3): 177-85.

http://dx.doi.org/10.1016/j.diabres.2003.07.002

[6] American Diabetes Association: Standards of medical care for patients with diabetes mellitus. Diabetes care. 2006 (suppl.1): 585.

[7] Smeltzer, B.C. et al. Brunner and Suddarth's Textbook of Medical Surgical Nursing 11th edition, Philadelphia. Lippincott Williams and Wilkins, 2008.

[8] Mohammed, Ashraf H. "Bringing Diabetes Under Control." Bringing Diabetes Under Control. 3 Jan. 2013 EzineArticles.com. 5 Jan. 2013.

[9] Jallinoja P, et al. The dilemma of patient responsibility for lifestyle change: perceptions among primary care physicians and nurses. Scand J Prim Health Care. 2007; 25(4): 244-9. http://dx.doi.org/10.1080/02813430701691778

[10] Uding J, et al. Efficacy of a teaching intervention on nurses' knowledge regarding diabetes. J Nurses Staff Dev. 2002; 18(6): 297-303. http://dx.doi.org/10.1097/00124645-200211000-00003

[11] McGowan P. The Efficacy of Diabetes Patient Education and Self-Management Education in Type 2 Diabetes Canadian Journal of Diabetes. 2011; 35(1): 46-5310.

[12] Funnell MM, Brown TL, Childs BP, et al. National standards for diabetes self-management education. Diabetes Care. 2009 ; 32 (suppl 1): S87-S94. http://dx.doi.org/10.2337/dc09-S087

[13] Kim, H. and Oh. Adherence to diabetes control recommendations: impact of nurse telephone calls: journal of Advanced Nursing. 2003; 44(3): 256-261.

[14] Ulrich, P A; Abner N, Meter, Meds, Meals, Move, and More A simple bedside approach to teaching diabetes self-management AJN. 2010; 110(7): 62-65.

[15] London F. No time to teach? A nurse's guide to patient and family education. Philadelphia: Lippincott; 1999.

[16] American Diabetes Association. Standards of medical care in diabetes-2009. Diabetes Care. 2009; 32 Suppl 1: S13-S61. http://dx.doi.org/10.2337/dc09-S013

[17] American Association of Diabetes Educators. Professional resources. AADE7 self-care behaviors. n.d. Available from: http://www.diabeteseducator.org/ProfessionalResources/AADE7

[18] Rubin DJ, Moshang J, Jabbour SA. Diabetes knowledge: are resident physicians and nurses adequately prepared to manage diabetes? Endocr Pract. 2007; 13(1): 17-21. http://dx.doi.org/10.4158/EP.13.1.17

[19] Peter, J. et al. What role do nurse play in Type 2 diabetes care in the community; a Delphi. Journal of Advanced Nursing. $2001 ; 34$ (2): 179-188. http://dx.doi.org/10.1046/j.1365-2648.2001.01743.x 
[20] Unwin N, Gan D, Whiting D. The IDF Diabetes Atlas: providing evidence, raising awareness and promoting action. Diabetes Res Clin Pract. 2010; 87(1): 2-314. http://dx.doi.org/10.1016/j.diabres.2009.11.006

[21] Ahmed et al. Diabetes related knowledge among residents and nurses: a multicenter study in Karachi, Pakistan BMC Endocrine Disorders. 2012; 12: 18. http://dx.doi.org/10.1186/1472-6823-12-18

[22] El-Deirawi KM, Zuraikat N. Registered nurses' actual and perceived knowledge of diabetes mellitus. J Nurses Staff Dev. 2001; 17(1): 5-11119. http://dx.doi.org/10.1097/00124645-200101000-00001

[23] Trepp R, Wille T, Wieland T, Reinhart WH. Diabetes-related knowledge among medical and nursing house staff. Swiss Med Wkly. 2012; 140(25-26): 370-375.

[24] S.P. Helmrich, D.R. Rayland, R.W. Leung, R.S. Paffenberger, Physical activity and reduced occurrence of NIDDM, New England Journal of Medicine. 1991; 325 (4): 147-151. http://dx.doi.org/10.1056/NEJM199107183250302

[25] International Diabetes Federation 2006: Global burden of diabetes. Diabetes atlas, www. Eatlas. Idf. Org/media. 2007, 3rd edition; 4-9. 